\title{
Sickle cell disease and age at menarche in Jamaican girls: observations from a cohort study
}

\author{
G R Serjeant, A Singhal, I R Hambleton
}

\begin{abstract}
Aims-(1) To investigate the distribution of age at menarche in a representative sample of 99 patients with homozygous sickle cell (SS) disease, 69 with sickle cell haemoglobin C (SC) disease, and 100 controls with a normal haemoglobin (AA) genotype followed in a cohort study from birth. (2) To explore the determinants of the age at menarche.

Methods-Children ascertained in a newborn screening programme were followed prospectively from birth to age 18-26.5 years with regular assessments of height, weight, pubertal stage, and haematological indices at the Sickle Cell Clinic of the University Hospital of the West Indies.

Results-All subjects have now reached menarche and the mean age in normal controls (13.0 years) was significantly earlier than in SC disease (13.5 years) or SS disease (15.4 years). Greater weight and earlier age at menarche was the only association significant across all genotypes although additional contributions occurred from fetal haemoglobin and red cell count in SS disease. Alpha thalassaemia, which ameliorates many of the effects of SS disease, had no discernible effect on menarche.

Conclusions-Mean age at menarche is delayed by 0.5 years in SC disease and by 2.4 years in SS disease. Weight appears to be the principle determinant of age at menarche.

(Arch Dis Child 2001;85:375-378)
\end{abstract}

Keywords: growth; menarche; sickle cell disease; body weight

The general retardation of sexual development in girls with homozygous sickle cell (SS) disease has been widely recognised since early descriptions by Winsor and Burch. ${ }^{12} \mathrm{Me}-$ narche was delayed by a mean interval of 1.7 years in Washington $\mathrm{DC},{ }^{3}$ and by $2.3-3.0$ years in different studies in Jamaica. ${ }^{4-6}$ Body weight and age were the best predictors of menarche in the Cooperative Study of Sickle Cell Disease in the USA, ${ }^{7}$ genotype contributing little after these factors were taken into account. A previous study in Jamaica identified fetal haemoglobin, and with less certainty, height and social class as the best predictors. ${ }^{6}$ The value of previous observations is generally limited by small patient groups, symptomatic bias in their selection, and often poorly matched controls. The Jamaican Cohort Study in which patients and controls have been followed from birth provides an opportunity to examine the effect of genotype and of other possible determinants on age at menarche in a representative sample of patients and controls.

\section{Patients and methods}

PATIENTS

The patients attended the Sickle Cell Clinic of the University Hospital of the West Indies and participated in a cohort study from birth. From June 1973 to December 1981, screening of 100000 consecutive deliveries at the main government maternity hospital (Victoria Jubilee Hospital) detected 315 babies with SS disease and 201 with sickle cell haemoglobin C (SC) disease who have been followed from birth in a cohort study. ${ }^{8}$ The first 125 babies with an SS phenotype were each matched with two controls of the same sex born closest in time (usually one born immediately before and one after), but with a normal haemoglobin (AA) phenotype providing 250 controls. Of the 368 females (129 normal haemoglobin (AA), $150 \mathrm{SS}, 89 \mathrm{SC}$ ) admitted to the study, 268 (100 AA, 99 SS, 69 SC) survived to the age of menarche and remained resident in Jamaica. Menarche had been prospectively recorded in all subjects by the study date $(31$ December 1999).

METHODS

Patients were followed at three to six month intervals at the Sickle Cell Clinic, and encouraged to attend at any time when sick; defaulters were actively traced, resulting in follow up rates of $100 \%$ and $96 \%$ for patients with SS and SC disease respectively. The clinic offered free health services, and was the preferred health care provider for patients, and the principle source of referral for hospital admission. At each clinic attendance, patients were questioned about clinical complications and hospital admissions since last seen, and relevant hospital notes were periodically reviewed. Clinic records are therefore believed to be reasonably complete and comprehensive.

\section{GROWTH DATA}

Observations at monthly intervals for the first six months and at bimonthly intervals for the second six months, measured weight on a sitting lever balance and length on a horizontal stadiometer. From the end of the first year, at three monthly intervals centred on the subject's birthday, weight was measured on a lever balance with the patient in light clothing and with shoes removed; height was measured using a wall mounted stadiometer accurate to $0.1 \mathrm{~cm}$ (Holtain Instruments Ltd). Measurements were made by the clinical nursing and 


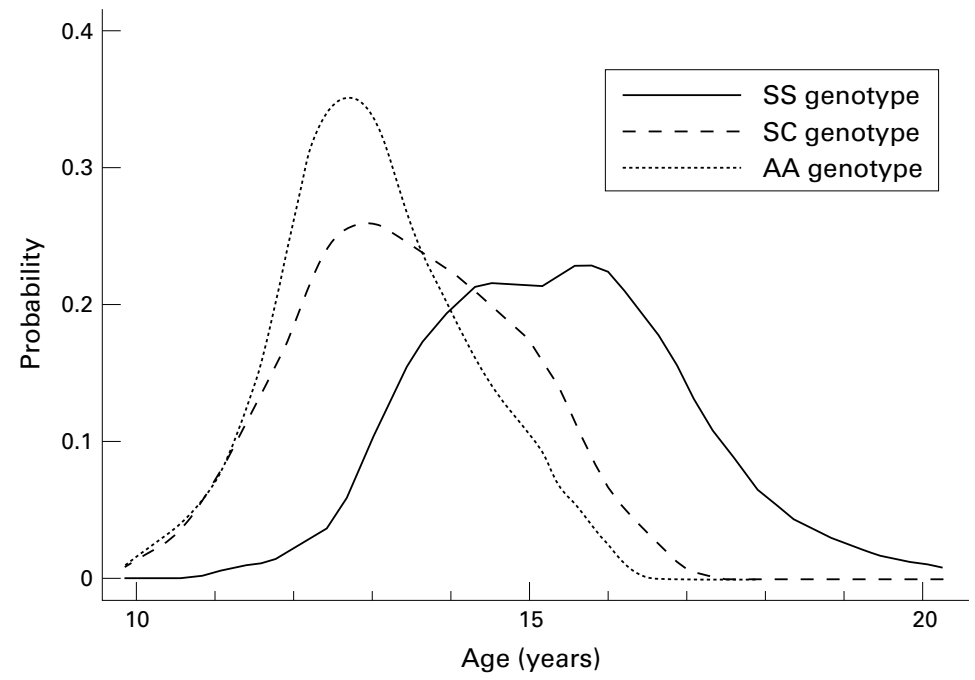

Figure 1 Distribution of age at onset of menarche among 100 AA genotype, 99 SS genotype, and 69 CS genotype subjects.

medical staff trained in the techniques involved. Pubertal development was assessed by Tanner staging at six monthly intervals coinciding with birthday visits. All girls were asked about menarche at each clinic visit; usually the exact date could be recalled.

Capillary blood samples were analysed at approximately two monthly intervals in the first year and venepunctures were performed annually on birthday visits or more frequently if clinically indicated. Haematological indices (total haemoglobin $(\mathrm{Hb})$, red cell count (RBC), mean cell volume (MCV), mean cell haemoglobin $(\mathrm{MCH})$, and platelets) were assessed in electronic counters (Models ZBI6, $S$ plus 4, MaxM; Coulter Electronics, Miami, Florida), packed cell volume (PCV) was measured as the spun microhaematocrit from which the mean cell haemoglobin concentration (MCHC) was calculated, and reticulocytes were counted manually after staining with brilliant cresyl blue. The total nucleated cell count (NBC) equated to white cell count with the exception of rare patients with sustained nucleated red cell counts, but routine correction for these was not applied. Fetal haemoglobin $(\mathrm{HbF})$ was assessed by alkali denaturation, ${ }^{10}$ and bilirubin by the method of Lathe and Ruthven. ${ }^{11}$ The number of alpha globin genes was determined on DNA from peripheral blood as described by Higgs and colleagues. $^{12}$

\section{STATISTICAL ANALYSIS}

The distribution of age at menarche was examined graphically for each genotype, and assessed formally using the Shapiro-Wilk test. ${ }^{13}$ Age at menarche was summarised by genotype using mean and standard deviation. The normality of age distribution and the fact that age at menarche was known in all subjects allowed the use of ordinary linear regression techniques. Potential determinants of age at menarche within each genotype were investigated using normal linear regression for individual indices and by a manual stepwise procedure, adjusting for the effects of other
Table 1 Mean delay in onset of menarche between genotypes

\begin{tabular}{llll}
\hline Genotype & $\begin{array}{l}\text { Menarche delay } \\
\text { years }(95 \% \text { CI })\end{array}$ & $\begin{array}{l}F \text { test } \\
(d f 1,265)\end{array}$ & p value \\
\hline SS v AA & $2.36(1.98,2.74)$ & 149.07 & $<0.001$ \\
SC v AA & $0.5(0.01,0.84)$ & 3.95 & 0.05 \\
SS v SC & $1.93(1.51,2.35)$ & 82.00 & $<0.001$ \\
\hline
\end{tabular}

significant indices. Annual measurements of potential determinants between 5 and 10 years of age were incorporated into the model using the method of Laird and Ware. ${ }^{14}$ Height and weight measurements collected on the subjects' birthday visits were used. Haematological indices $(\mathrm{Hb}, \mathrm{PCV}, \mathrm{RBC}, \mathrm{MCV}, \mathrm{MCH}$, MCHC, NBC, reticulocytes, platelets, and $\mathrm{HbF}$ ) and direct reacting bilirubin were averaged for each year of life. The number of alpha globin genes was available in $97 \% \mathrm{AA}$, $100 \%$ SS, and $99 \%$ SC patients reaching menarche. The final model was chosen using the adjusted coefficient of multiple determination (adjusted $\mathrm{R}^{2}$ ), a common criteria for evaluating the adequacy of models. Regression coefficients should be interpreted as the years of menarche delay for each unit increase in a potential determinant. Significance was assumed at the 5\% level and marginally significant results are presented. All analyses were conducted using commercially available software (StataCorp, 2001, Stata Statistical Software: Release 7.0, Stata Corporation, College Station, Texas).

\section{Results}

Three patients were excluded from analysis because of other conditions likely to have affected recall of, or age at, menarche. These included an AA subject who defaulted between the ages of 6 months and 20 years 2 months and in whom recall was considered inaccurate, and two SC subjects with genetic conditions influencing menarche (one sex chromosome anomaly and one trisomy $9 \mathrm{p}$ syndrome). With these exceptions, all patients have now entered menarche.

The distributions of age at menarche for each genotype were not significantly nonnormal (Shapiro-Wilk test: AA p $=0.41$, SC $\mathrm{p}=0.62$, SS $\mathrm{p}=0.38)$. The mean age of menarche was 13.0 years in AA controls (SD 1.1 years), 13.5 years in SC disease (SD 1.3 years), and 15.4 years in SS disease (SD 1.6 years). Figure 1 shows age at menarche in the three genotypes; it was significantly delayed in SS and SC genotypes compared to AA controls, and in SS compared to SC genotypes (table 1).

Preliminary inspection of haematological indices indicated (as expected) strong positive correlations between $\mathrm{Hb}, \mathrm{PCV}$, and $\mathrm{RBC}$ in all genotypes and between $\mathrm{HbF}$ and these three indices in SS disease, all significant at the 5\% level after correction for multiple testing. Multiple linear regression was necessary to allow for correlations between these potential predictors (table 2). Four subjects (three SC, one AA) lacked haematological information between 5 and 10 years, reducing the sample for 
Table 2 Relation of some growth and haematological indices to onset of menarche among 99 patients with SS disease

\begin{tabular}{|c|c|c|c|c|c|c|c|c|}
\hline \multirow[b]{2}{*}{ Term } & \multicolumn{4}{|c|}{ Individual regression } & \multicolumn{4}{|c|}{ Stepwise regression } \\
\hline & $\begin{array}{l}\text { Regression } \\
\text { coefficient }\end{array}$ & $95 \% C I$ & $p$ value & $\begin{array}{l}\text { Model fit } \\
\text { (adjusted } R^{2} \text { ) }\end{array}$ & $\begin{array}{l}\text { Regression } \\
\text { coefficient }\end{array}$ & $95 \% C I$ & $p$ value & $\begin{array}{l}\text { Model fit } \\
\text { (adjusted } R^{2} \text { ) }\end{array}$ \\
\hline Weight (kg) & -0.30 & $-0.43,-0.17$ & $<0.001$ & 0.16 & -0.21 & $-0.33,-0.10$ & $<0.001$ & $0.25^{\star}$ \\
\hline Height $(\mathrm{cm})$ & -0.11 & $-0.16,-0.06$ & $<0.001$ & 0.14 & - & - & - & \\
\hline $\mathrm{Hb}(\mathrm{g} / \mathrm{l})$ & -4.6 & $-8.0,-1.2$ & 0.009 & 0.06 & - & - & - & \\
\hline $\operatorname{PCV}(\%)$ & -0.17 & $-0.28,-0.06$ & 0.004 & 0.08 & - & - & - & \\
\hline $\mathrm{RBC}\left(\times 10^{12} / 1\right)$ & -1.24 & $-1.99,-0.48$ & 0.002 & 0.09 & -0.79 & $-1.55,-0.04$ & 0.04 & \\
\hline $\operatorname{MCV}(\mathrm{fl})$ & 0.02 & $-0.02,0.07$ & 0.35 & 0 & - & - & - & \\
\hline $\mathrm{MCH}(\mathrm{pg})$ & 0.09 & $-0.03,0.20$ & 0.14 & 0.01 & - & - & - & \\
\hline $\operatorname{MCHC}(\mathrm{g} / \mathrm{l})$ & 1.5 & $-0.9,3.9$ & 0.21 & 0.01 & - & - & - & \\
\hline Reticulocytes (\%) & 0.14 & $-0.03,0.26$ & 0.02 & 0.05 & - & - & - & \\
\hline NBC $\left(\times 10^{9} / 1\right)$ & 0.14 & $0.08,0.20$ & $<0.001$ & 0.15 & - & - & - & \\
\hline Platelets $\left(\times 10^{9} / 1\right)$ & 0.0017 & $-0.0010,0.0043$ & 0.21 & 0.01 & - & - & - & \\
\hline $\mathrm{HbF}(\%)$ & -0.13 & $-0.20,-0.06$ & $<0.001$ & 0.12 & -0.07 & $-0.14,0.004$ & 0.06 & \\
\hline Direct bilirubin & 0.03 & $-0.07,0.12$ & 0.56 & 0.01 & - & - & - & \\
\hline \multicolumn{9}{|l|}{ Alpha globin genes } \\
\hline 3 gene $v 4$ gene & -0.15 & $-0.82,0.53$ & 0.66 & 0.01 & - & - & - & \\
\hline 2 gene $v 4$ gene & -1.42 & $-3.01,0.17$ & 0.08 & & - & - & - & \\
\hline
\end{tabular}

${ }^{\star}$ Model fit for final regression based on weight, RBC, and $\mathrm{HbF}$.

these analyses to 264 (99AA, 99SS, 66SC). In SS and SC disease, univariate contributions from $\mathrm{Hb}, \mathrm{PCV}$, reticulocytes, NBC, and alpha globin gene number disappeared on multiple regression, leaving modest effects of red cell count and $\mathrm{HbF}$. Weight was clearly the dominant factor for all three genotypes. Alpha thalassaemia, believed to ameliorate end organ damage in SS disease, had no discernible effect on age at menarche.

The final regression model indicates that menarche in SS disease was delayed by 37-119 days for every $1 \mathrm{~kg}$ decrease in weight, 15-564 days for every $1 \times 10^{12} / 1$ increase in red cell count, and 2-50 days for every $1 \%$ decrease in $\mathrm{HbF}$. In SC disease, menarche was delayed by 20-84 days for every $1 \mathrm{~kg}$ decrease in weight, 54-544 days for every $1 \times 10^{12} / 1$ increase in red cell count, and 10-152 days for every 1\% decrease in $\mathrm{HbF}$. Among AA control subjects, menarche was delayed by 29-72 days for every $1 \mathrm{~kg}$ decrease in weight.

\section{Discussion}

Previous studies on menarche and delayed sexual development in sickle cell disease were based on symptomatically selected patient groups, a bias which might be expected to favour more severely affected patients. Some studies have combined data from different genotypes of sickle cell disease which are known to have differing effects on growth. Furthermore, specific control groups with a normal haemoglobin genotype have not been available and comparisons have been made with national surveys or less appropriate comparison groups. The use of historical control data may lead to inaccuracy because of the secular effect of earlier menarche with time. Recall of age at menarche is notoriously unreliable and some studies have avoided this inaccuracy by cross sectional studies inquiring of patients at different ages whether or not they had attained menarche. The present study has avoided these potential sources of inaccuracy by prospectively following large groups of patients with SS and SC disease and matched controls with a normal haemoglobin genotype ascertained at birth and recording menarche as it occurred.
Among normal Jamaican children the mean age of menarche of 13.0 years was delayed by 0.5 years in SC disease and by 2.4 years in SS disease, both differences reaching statistical significance. Examination of possible determinants revealed weight to be the only consistent factor across all genotypes, consistent with observations from the Cooperative Study in the USA. ${ }^{7}$ A search for potential haematological determinants of menarche in SS disease revealed significant contributions from total haemoglobin, packed cell volume, red cell count, reticulocytes, nucleated cell count, and fetal haemoglobin, but after multiple regression only weak effects of fetal haemoglobin and red cell count persisted, indicating that many of the other apparent effects were accounted for by their interrelations. It was interesting to note that alpha thalassaemia, a factor believed to inhibit tissue damage, did not contribute to the final model. Fetal haemoglobin appears to ameliorate many of the pathological consequences of SS disease, and the lack of a stronger effect was surprising. However, although high concentrations of $\mathrm{HbF}$ were associated with greater prepubertal growth in weight and height in males, ${ }^{15}$ no effect was discernible on prepubertal growth in girls, consistent with the weak effect of $\mathrm{HbF}$ on age at menarche.

The current data on age at menarche are consistent with previous work from Jamaica in SS disease, which reported a mean age of 15.4 years compared with 13.1 years in normal controls, ${ }^{4}$ and a median age of 15.7 years (mean 16.1) compared with 12.0 years (mean 12.7) in normal controls. ${ }^{6}$ A search for predictive factors in the latter report using stepwise regression noted significant effects of $\mathrm{HbF}$, social status, and height, broadly similar to the present analysis.

We have identified weight as the clearly dominant factor in all genotypes, similar to observations elsewhere in the general population $^{16}$ and in sickle cell disease. ${ }^{7}$ This argues against an endocrine component delaying pubertal development and is consistent with the hypothesis that suboptimal nutrition, resulting from a failure to increase energy intake to compensate adequately for the 
increased metabolic demands in sickle cell disease, ${ }^{17}$ may delay physical and sexual development in the disease.

We thank Professor Douglas Higgs of the Weatherall Institute of Molecular Medicine, Oxford for the determination of globin gene number.

1 Winsor T, Burch GE. The habitus of patients with sickle cell anemia. Hum Biol 1944;16:99-114.

2 Winsor T, Burch GE. Habitus of patients with active sickle cell anemia of long duration. Arch Intern Med 1945;76:4753.

3 Jiminez CT, Scott RB, Henry WL, et al. Studies in sickle cell anemia. XXVI. The effects of homozygous sickle cell disease on the onset of menarche, pregnancy, fertility, pubescent changes, and body growth in Negro subjects. Am f Dis Child 1966;111:497-504.

4 Alleyne SI, D'Hereux Rauseo R, Serjeant GR. Sexual development and fertility of Jamaican female patients with opment and fertility of Jamaican female patients with homozygou $1295-7$.

5 Ashcroft MT, Serjeant GR. Growth, morbidity, and mortality in a cohort of Jamaican adolescents with homozygous sickle cell disease. W Ind Med f 1981;30:197201

6 Graham C, Maude GH, Serjeant GR. Delayed menarche in homozyous sickle cell disease. W Ind Med f 1986;35:18-22.
7 Platt OS, Rosenstock W, Espeland MA. Influence of sickle hemoglobinopathies on growth and development. N Engl $\mathcal{F}$

8 Serjeant BE, Forbes M, Williams LL, Serjeant GR. Screening cord bloods for detection of sickle cell disease. Clin Chem 1974;20:666-9.

9 Serjeant GR, Serjeant BE, Forbes M, et al. Haemoglobin gene frequencies in the Jamaican population: a study of 100,000 newborns. Br F Haematol 1986;64:253-62.

10 Betke K, Marti HR, Schlicht I. Estimation of small percentages of foetal haemoglobin. Nature 1959;184:1877-8.

11 Lathe GH, Ruthven CRJ. Factors affecting the rate of coupling of bilirubin and conjugated bilirubin in the Van Den Bergh reaction. F Clin Pathol 1962;11:155-61.

12 Higgs DR, Aldridge BE, Lamb J, et al. The interaction of alpha-thalassemia and homozygous sickle-cell disease. $N$ Engl f Med 1982;306:1441-6.

13 Royston P. A toolkit for testing nonnormality in complete and censored samples. Statistician 1993;42:37-43.

14 Laird NM, Ware JH. Random-effects models for longitudinal data. Biometrics 1982;38:963-74.

15 Singhal A, Morris J, Thomas P, et al. Factors affecting prepubertal growth in homozygous sickle cell disease. Arch Dis pubertal growth in hon $1996 ; 74: 502-6$.

16 Frisch RE, Ravelle R. Height and weight at menarche and a hypothesis of critical body weights and adolescent events. Science 1970;169:397-9.

17 Singhal A, Davies P, Wierenga KJJ, et al. Is there an energy deficiency in homozygous sickle cell disease? Am $\mathcal{F}$ Clin Nutr 1997;66:386-90.

\section{7th European Forum on Quality Improvement in Health Care}

\section{1-23 March 2002 \\ Edinburgh, Scotland}

We are delighted to announce this forthcoming conference in Edinburgh. Delegate enquiries are welcome.

The themes of the Forum are:

- Leadership, culture change, and change management

- Achieving radical improvement by redesigning care

- Health policy for lasting improvement in health care systems

- Patient safety

- Measurement for improvement, learning, and accountability

- Partnership with patients

- Professional quality: the foundation for improvement

- Continuous improvement in education and training

- People and improvement.

Presented to you by the BMJ Publishing Group (London, UK) and Institute for Healthcare Improvement (Boston, USA). For more information contact: quality@bma.org.uk or look at the website www.quality.bmjpg.com. Tel: +44 (0)20 7383 6409; fax: +44 (0)20 73736869 . 